\title{
Tuning Polymer-Grafted Particle Monolayer Structure at the Air-Water Interface by Introducing Anisotropic Features
}

\author{
Emiko Mouri, Yo Yamasaki, Motokazu Terada \\ Department of Applied Chemistry, Kyushu Institute of Technology, Kyushu Institute of Technology, Fukuoka, Japan \\ Email:mouri@che.kyutech.ac.jp
}

How to cite this paper: Mouri, E., Yamasaki, Y. and Terada, M. (2018) Tuning Polymer-Grafted Particle Monolayer Structure at the Air-Water Interface by Introducing Anisotropic Features. Journal of Materials Science and Chemical Engineering, 6, 11-18.

https://doi.org/10.4236/msce.2018.61002

Received: October 4, 2017

Accepted: January 1, 2018

Published: January 4, 2018

\begin{abstract}
Fabrication of anisotropic material is one of the important topics and we examined to introduce "anisotropic" nature by spreading polymer-grafted particle on the medium with polymer-reactive potential. Poly (tert-butyl methacrylate) (PtBMA) was polymerized from polystyrene latex (PSL) surface by ATRP to give P $t$ BMA-grafted PSL (PSL-P $t$ BMA). Particle monolayer was formed at air-water and air-acidic water interfaces and the monolayer characteristics were compared by $\pi-\mathrm{A}$ isotherm measurements, SEM observations, and contact angle measurements. $\pi$ - $\mathrm{A}$ isotherms, in particular, indicates that the interaction between polymer chains become stronger by changing the subphase condition, which suggests that anisotropicparticle monolayer formation.
\end{abstract}

\section{Keywords}

Anisotropic Particle, Polymer-Grafted Particle, Air-Water Interface,

Polymer Brush, Particle Monolayer

\section{Introduction}

A particle at interface is a simplest system concerning interfaces and has wide variety of interests ranging from basic science to industrial process [1]. Among the particulate fabrications, in particular, there has been a great interest in creating materials with anisotropic property. One is to fabricate materials with anisotropic shape such as disc or rod. Another is to make anisotropic nature with spherical shape, i.e., Janus particles [2] [3]. In the latter category, preparation process is further categorized into two. One is to making use of association behavior like micelle or emulsion including non-equilibrium status [4] [5] [6] 
[7] [8]. The other is to utilizing the planner interface, for example, air/water interface or liquid/liquid interface [9] [10] [11] [12], which concerns the topic of this paper.

In this paper, we describe the fabrication of polymer-grafted particle monolayer with anisotropic features introduced at the air-aqueous medium interface. We have been studying polymer-grafted particle system at the air-water and oil-water interfaces [13]-[18]. We systematically investigated the effects of molecular weight, graft density, core particle, polymer species, and interface on the polymethacrylate-grafted particle monolayer structure by $\pi$-A isotherm measurement, SEM observation and X-ray reflectivity measurement. So far, we found that polymethacrylate-grafted particles forms monolayer at air-water interface and grafted polymethacrylate chains are fairly extended at the interfaces. On the basis of these previous findings, we verified to fabricate anisotropic polymer-grafted particle by utilizing potential reactivity at the air/water interface.

\section{Experimental Method}

\subsection{Synthesis and Characterization of PtBMA-Grafted Polystyrene Latex}

Polystyrene latex with chloromethyl groups was synthesized by soap-free emulsion polymerization as previously described [16]. The averaged diameter of polystyrene latex was estimated by dynamic light scattering with DLS-8000 (Otsuka Electronics Co., Ltd., Hirakata, Japan). Polydispersity was confirmed to be within $1 \%$. Graft polymerization of PMMA from polystyrene latex surface via copper-mediated ATRP was carried out as follows [15] [19]: The polystyrene latex dispersion of $\mathrm{DME}$ was mixed with freshly distilled $\mathrm{P} t \mathrm{BMA}, \mathrm{CuBr}$ (I) and $N, N, N^{\prime}, N^{\prime \prime}, N^{\prime \prime}$-pentamethyldiethylenetrimamime (PMDETA). The mixture was carefully bubbled and degassed by ultrasonification under argon atmosphere. Then free initiator, $\alpha$-chloro- $p$-xylene, was added to the mixture. Typical feed is $40 \mathrm{mg}$ of polystyrene latex, $6.6 \mathrm{ml}$ of dry MMA, $7 \mathrm{mg}$ of $\mathrm{CuBr}$, and $32 \mathrm{mg}$ of PMDETA with $6.4 \mathrm{mg}$ of free initiator. The solution was degassed by four or five freeze-pump-thaw cycles and the ample was sealed off completely with argon purge. The polymerization was carried out at $80^{\circ} \mathrm{C}$ for 4 days to obtain $\mathrm{P} t \mathrm{BMA}$-grafted polystyrene latex (PSL-P $t \mathrm{BMA})$.

Molecular weight and polydispersity of free polymer were confirmed by GPC equipped with column oven (CTO-10A/10AC, Shimadzu, Kyoto, Japan) and refractive index detector (RI153, JASCO Corp., Tokyo, Japan). Obtained polymer-grafted particle was firstly characterized by dynamic light scattering (DLS). Time correlation function was fitted to single exponential function, and hydrodynamic diameter and high monodispersity was confirmed.

Estimation of graft density is performed by utilizing IR spectrum measurement as follows: Calibration curves for $\mathrm{P}(t \mathrm{BMA})$ and PSL was obtained respectively with 2-cyanoacetoamide as internal standard as same as previous study 
[16]. The following peaks were picked up for calibration curves; $1475 \mathrm{~cm}^{-1}$ (PSL, benzene ring in-plane vibration), $1140 \mathrm{~cm}^{-1}$ (P $t \mathrm{BMA}, \mathrm{C}-\mathrm{O}$ stretching), and 2270 $\mathrm{cm}^{-1}$ (cyanoacetoamide, $\mathrm{C} \equiv \mathrm{N}$ stretching). The linier relationships were obtained between molar ratio of $[t \mathrm{BMA}] /[2$-cyanoacetoamide] (or [styrene]/[2-cyanoacetoamide]) and peak area ratio [C-O stretching]/[ $\mathrm{C} \equiv \mathrm{N}$ stretching] (or [benzene ring in-plane vibration]/[ $\mathrm{C} \equiv \mathrm{N}$ stretching]). By IR measurement of PSL-P $t$ BMA as in Figure 1, the amount ratios of P $t$ BMA to PSL were obtained for each sample. Then, the graft density of $\mathrm{P} t \mathrm{BMA}$ was calculated with the two assumptions that 1 ) the molecular weight of grafted $\mathrm{P} t \mathrm{BMA}$ is equal to $M_{n}$ obtained by GPC, and 2) polystyrene latex was made of only polystyrene with density of 1.047 .

\subsection{Preparation of PMMA-Grafted Polystyrene Latex Monolayer and Measurement of $\pi-A$ Isotherms}

The preparation of particle monolayer was carried out as previously reported [13]-[18]. The chloroform solution of $2.5 \times 10^{-4} \mathrm{~g} / \mathrm{ml}$ PSL-P $t$ BMA was spread by microsyringe on ultra-pure water surface and $\mathrm{HCl}$ solution $(\mathrm{pH} 3)$, respectively in Langmuir-Blodgett $(\mathrm{LB})$ trough $(150 \mathrm{~mm} \times 160 \mathrm{~mm})$. After evaporation of solvent, the water surface was compressed and expanded by Teflon barrier at $0.025 \mathrm{~mm} / \mathrm{sec}$ to measure $\pi$-A isotherm at $25^{\circ} \mathrm{C}$ by USI-3-00 (USI System, Fukuoka, Japan). At various surface pressures on a second compression, particle layer was deposited on glass plate by LB method at the speed of $10 \mathrm{~mm} / \mathrm{min}$. We observed the deposited particle layers by SEM (SM-7000FSK, JEOL Ltd., Tokyo, Japan). In order to estimate the basic property of a deposited layer on a substrate, contact angle measurement was measured by dropping $0.5 \mu \mathrm{L}$ pure water on a substrate and observing the drop shape by a digital camera with a-close-up lens [16].

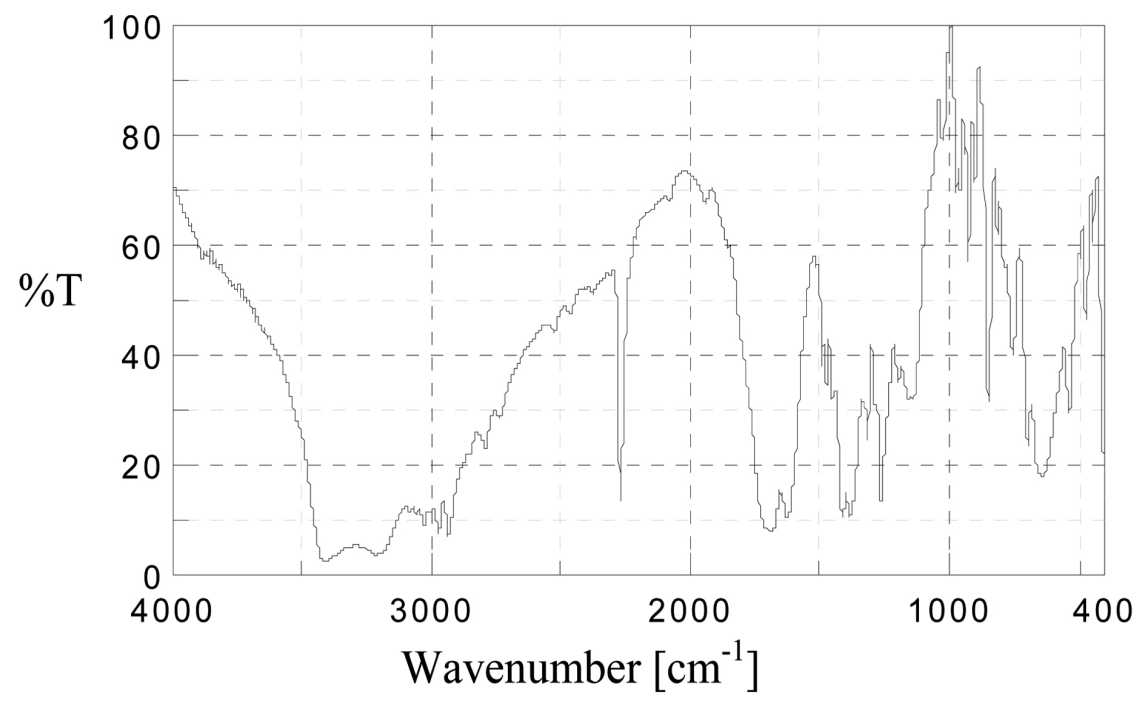

Figure 1. IR spectrum for PSL-P $t$ BMA added with cyanoacetoamide with internal standard. 


\section{Results and Discussion}

The characteristics of core PS particle and PSL-P $t$ BMA are summarized in Table 1 and Table 2, respectively. Important parameters for PSL-P $t$ BMA, molecular weight of grafted polymers, graft density and hydrodynamic size in the solution, are summarized in Table 2. Although we obtained $\mathrm{P} t \mathrm{BMA}$ homopolymer with high monodisperse nature $\left(M_{w} / M_{n}=1.15-1.24\right)$ in the comparable system without PSL, P $t$ BMA molecular weight with PSL showed wider molecular weight distribution. Since the hydrodynamic size of PSL used here is $118 \mathrm{~nm}, \mathrm{P} t \mathrm{BMA}$ brush layer with ca.10-nm thickness covers around PSL latex core. The graft density of 0.14 is relative high graft density [13]-[18].

PSL-P $t$ BMA of well-characterized sample is applied to monolayer formation at the air/water interface. Figure 2 shows the $\pi$-A isotherm of PSL-P $t$ BMA at the air-water interface as curve 1 . The $\pi$-A isotherm is reproducible and shows the increase of surface pressure at a very large occupied area. For example, expected occupied area with PSL particles with closest packing is indicated by straight line in Figure 1, which shows more than 1/10 smaller area. As also discussed in the

Table 1. Characteristics of PSL.

\begin{tabular}{ccc}
\hline Sample code & $\mathrm{D}_{\mathrm{h}} / \mathrm{nm}$ & Polydispersity \\
\hline PSL & 118 & 0.050 \\
\hline
\end{tabular}

Table 2. Characteristics of PSL-P $t$ BMA.

\begin{tabular}{ccccc}
\hline Sample code & $\mathrm{M}_{\mathrm{n}}$ & $\mathrm{M}_{\mathrm{w}} / \mathrm{M}_{\mathrm{n}}$ & Graft density $/ \mathrm{nm}^{-2}$ & $\mathrm{D}_{\mathrm{h}} / \mathrm{nm}$ \\
\hline PSL-P $t$ BMA & 76,000 & 1.41 & 0.113 & 144 \\
\hline
\end{tabular}

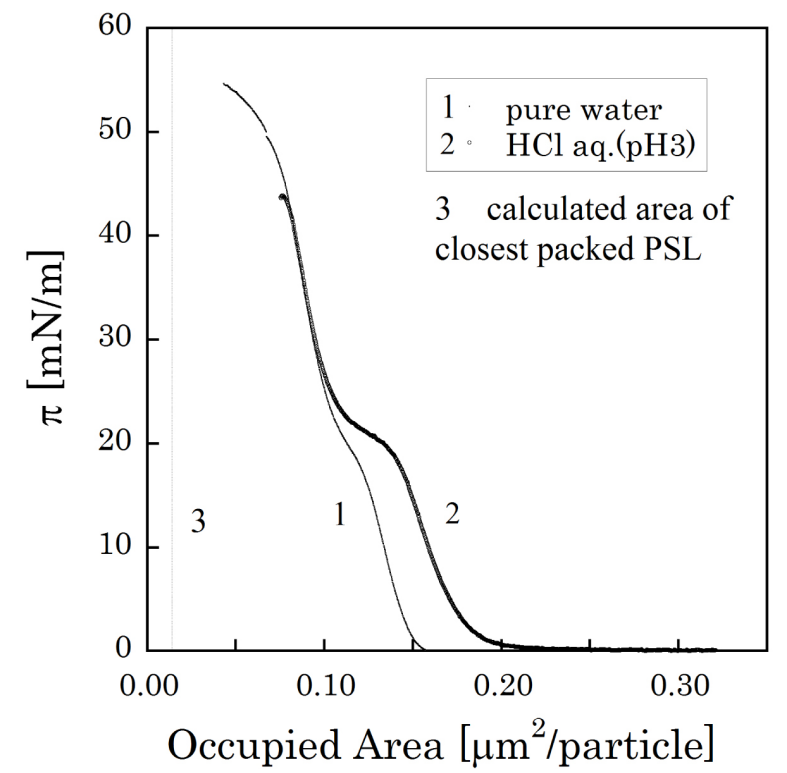

Figure 2. $\pi-\mathrm{A}$ isotherms for PSL-P $t \mathrm{BMA}$ on a pure water and on a $\mathrm{HCl}$ aqueous solution. Straight line indicates the occupied area of PSL core at closest packing. 
former our papers, this indicates that polymer chains grafted from particles are much extended on the water surface [15] [16]. In this data, the occupied area at $1 \mathrm{mN} / \mathrm{m}$ is corresponds to the interparticle distance of $388 \mathrm{~nm}$ assuming closest packing of particle at the air-water interface. On the other hand, calculated interparticle distance with stretched conformation of $M_{n}=76,000$ is to be $386 \mathrm{~nm}$. These two values are in agreement. We do know that the molecular weight used here is relative value and contains errors, however, the agreement of these values supports the extended fairly conformation of $\mathrm{P} t \mathrm{BMA}$ on a watersurface similar to PMMA system [16].

SEM images of deposited monolayer by LB method at several constant surface pressuresare presented in Figures 3(a)-(c). These SEM images support the monolayer formation, not multilayer. We can see individual PSL core with separation of more than $150 \mathrm{~nm}$.

In order to introduce "anisotropicity" in the particle monolayer by utilizing the nature of air-water interface, monolayer formation of PSL- $t$ BMA is conducted on acidic aqueous solution of $\mathrm{pH} 3$. Partial proceeding of $\mathrm{P} t \mathrm{BMA}$ hydrolysis in water subphase may occur because the hydrolysis of P $t \mathrm{BMA}$ into PMAA is irreversible reaction while $\mathrm{P} t \mathrm{BMA}$ remains at the air side. However, the acidic condition here is milder than usual hydrolysis condition for PtBMA [20] [21]. Thus, small fraction of $t$ BMA monomer units would be hydrolyzed to give methacrylic acid units.

In Figure 2, $\pi$-A isotherm obtained on acidic subphase is also presented as curve 2 . The $\pi$-A isotherm on acidic subphase shows clear shift to larger occupied area before plateau region. On the other hand, two $\pi$-A isotherms at different conditions match after plateau region. Based our previous data, below the plateau region the interaction between polymer chains grafted from particle is observed while the interaction between hard spheres is observed above the plateau region [16]. Considering the interpretation of $\pi-\mathrm{A}$ isotherm, it is reasonable
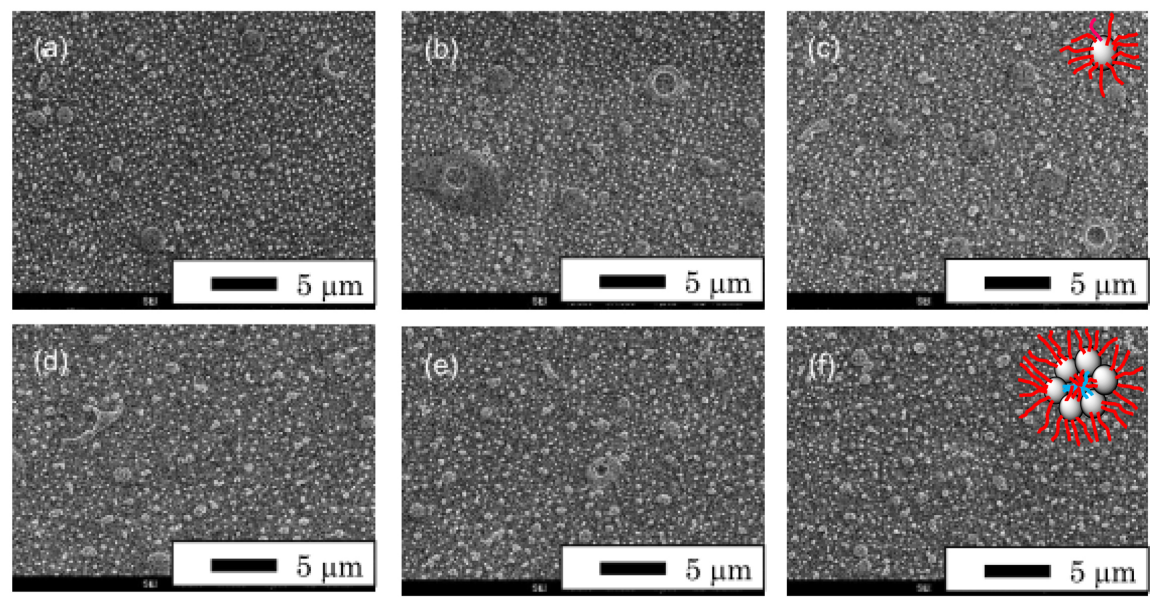

Figure 3. SEM images of deposited PSL-P $t$ BMA monolayer on glass substrates at constant surface pressures ((a), (d): $10 \mathrm{mN} / \mathrm{m},(b),(e): 15 \mathrm{mN} / \mathrm{m},(\mathrm{c})$ (f): $30 \mathrm{mN} / \mathrm{m}$ ) from pure water (a)-(c) and $\mathrm{HCl}$ aq. solution (d)-(f). Schematic figures are also shown. 
that the difference between the $\pi$ - $\mathrm{A}$ isotherms are observed only below the plateau region. In addition to that, assuming the hydrolysis proceeds in some part, the interaction between PMAA (the resultant of hydrolysis of PtBMA) is enhanced little bet by the electrostatic interaction (although almost MAA is not dissociated in acidic $\mathrm{pH}$ range), which agrees with the tendency that surface pressure is increased at the larger occupied area.

SEM images of deposited monolayer by LB method at several constant surface pressures are presented in Figures 3(d)-(f). SEM images obtained at acidic condition shows more aggregated states than the ones at the air-water interface. The anisotropic nature of PSL-P $t$ BMA at acidic condition would favors formation of large assembly of polymer-grafted PSL although we cannot ascertain whether the large aggregates are formed at the water surface or at the glass substrates.

We also estimate the surface property of deposited particle monolayer on substrate. Figure 4 shows variation of contact angle of water droplet on the particle monolayers with varying surface pressure. The values of contact angles are similar at the two different subphase conditions above $5 \mathrm{mN} / \mathrm{m}$. This is rather reasonable that the outer surface would be P $t \mathrm{BMA}$ because particle monolayer is deposited as $\mathrm{Y}$ type. In the studied range, aggregation shown in Figure 3 is not so effective to the contact angels. By changing the substrate to more hydrophobic one, we could tune the contact angle by PSL-P $t$ BMA from acidic subphase.

\section{Conclusion}

In the view of fabricating anisotropic particles monolayer, we investigated the behavior of PSL-P( $t$-butyl methacrylate) at the air/acidic water interface. P $t \mathrm{BMA}$ was polymerized from monodisperse polystyrene latex (PSL) surface by ATRP to givemonodisperse P $t$ BMA-grafted PSL (PSL-P $t$ BMA). PSL-P $t$ BMA monolayer was characterized by $\pi$-A isotherms and SEM. PSL-P $t$ BMA monolayer deposited from acidic condition shows more aggregated state on glass substrate rather than the ones deposited from pure water, however, the contact angle of the both

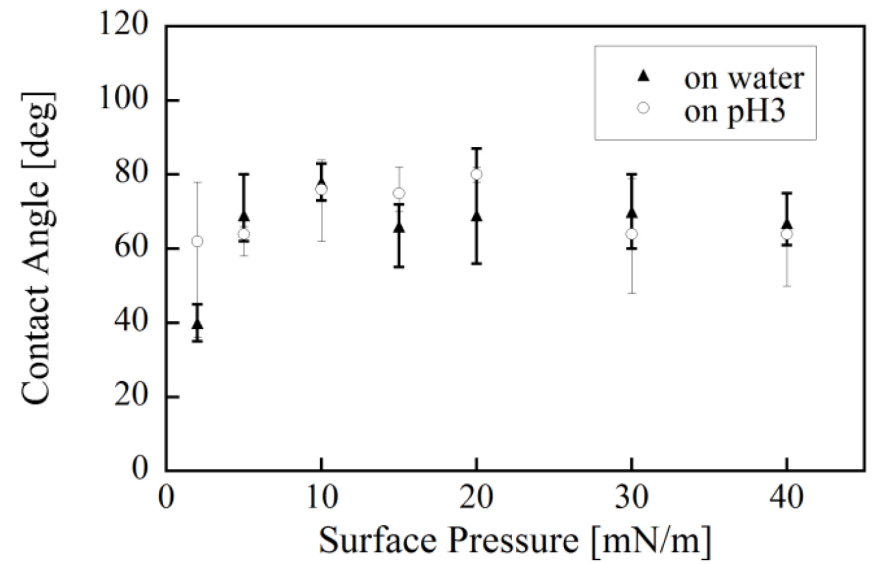

Figure 4. Contact angle of water droplets measured on PSL-P $t$ BMA monolayer deposited on glass substrates at constant surface pressures with different subphase conditions. 
deposited film shows similar values.

\section{Acknowledgements}

We are greatly thankful to Prof. Kohji Yoshinaga (Professor Emeritus of Kyushu Institute of Technology) for his advice in the experiments especially for the synthesis of the samples. This work was financially supported by a grant-in-aid (No. 19750099, 24850015) from JSPS.

\section{References}

[1] Binks, B.P. and Horozov, T.S. (2006) Colloidal Particles at Liquid Interfaces. Cambridge University Press, Cambridge. https://doi.org/10.1017/CBO9780511536670

[2] Perro, A., Reculusa, S., Ravaine, S., Bourgeat-Lami, E. and Duguet, E. (2005) Design and Synthesis of Janus Micro- and Nanoparticles. Journal of Materials Chemistry, 15, 3745-3760. https://doi.org/10.1039/b505099e

[3] Walther, A. and Muiller, A.H.E. (2013) Janus Particles: Synthesis, Self-Assembly, Physical Properties, and Applications. Chemical Reviews, 113, 5194-5261. https://doi.org/10.1021/cr300089t

[4] Hong, L., Jiang, S. and Granick, S. (2006) Simple Method to Produce Janus Colloidal Particles in Large Quantity. Langmuir, 22, 9495-9499. https://doi.org/10.1021/la062716z

[5] Liu, B., Wei, W., Qu, X. and Yang, Z. (2008) Janus Colloids Formed by Biphasic Grafting at a Pickering Emulsion Interface. Angewandte Chemie, 120, 4037-4039.

[6] Wurm, F. and Kilbinger, A.F.M. (2009) Polymeric Janus Particles. Angewandte Chemie International Edition, 48, 8412-8421. https://doi.org/10.1002/anie.200901735

[7] Yabu, H., Koike, K., Motoyoshi, K., Higuchi, T. and Shimomura, M. (2010) A Novel Route for Fabricating Metal-Polymer Composite Nanoparticles with Phase-Separated Structures. Macromolecular Rapid Communications, 31, 1267-1271. https://doi.org/10.1002/marc.201000007

[8] Jiang, S., Chen, Q., Tripathy, M., Luijten, E., Schweizer, K.S. and Granick, S. (2010) Janus Particle Synthesis and Assembly. Advanced Materials, 22, 1060-1071.

[9] Paunov, V.N. and Cayre, O.J. (2004) Supraparticles and "Janus" Particles Fabricated by Replication of Particle Monolayers at Liquid Surfaces Using a Gel Trapping Technique. Advanced Materials, 16, 788-791. https://doi.org/10.1002/adma.200306476

[10] Glaser, N., Adams, D.J. and Bőr, A. (2006) Janus Particles at Liquid-Liquid Interfaces. Langmuir, 22, 5227-5229.

[11] Pradhan, S., Xu, L.-P. and Chen, S. (2007) Janus Nanoparticles by Interfacial Engineering. Advanced Functional Materials, 17, 2385-2392. https://doi.org/10.1002/adfm.200601034

[12] Fujii, S., Kappl, M., Butt, H.-J., Sugimoto, T. and Nakamura, Y. (2012) Soft Janus Colloidal Crystal Film. Angewandte Chemie, 124, 9947-9951. https://doi.org/10.1002/ange.201204358

[13] Mouri, E., Okazaki, Y., Tatsuno, S., Karakawa, H. and Yoshinaga, K. (2006) Particle Monolayer Formation at the Air-Water Interface by Silica Particle with Well-Defined Grafted Polymer. Journal of Polymer Science Part B, 44, 2789-2797. https://doi.org/10.1002/polb.20935 
[14] Mouri, E., Okazaki, Y., Yoshinaga, K. and Matsuoka, H. (2009) X-Ray Reflectometry Confirms Polymer-Grafted Silica Particle Monolayer Formation at the Air-Water Interface. Journal of Nanoscience and Nanotechnology, 9, 327-333. https://doi.org/10.1166/jnn.2009.J038

[15] Mouri, E., Okazaki, Y., Komune, S. and Yoshinaga, K. (2011) Effect of Grafted Polymer Species on Particle Monolayer Structure at the Air-Water Interface. Journal of Nanoscience and Nanotechnology, 11, 2486-2495.

[16] Mouri, E., Terada, M., Koga, R., Karakawa, H. and Yoshinaga, K. (2010) Particle Monolayer Formation with Arrayed Structure by PMMA-grafted Polystyrene Latex at the Air-Water Interface. Journal of Nanoscience and Nanotechnology, 10, 5838-5846. https://doi.org/10.1166/jnn.2010.2470

[17] Moon, J.-M., Kim, B.-B., Paik, H.-J., Lee, J.-O., Mouri, E. and Yoshinaga, K. (2010) Structural Estimation of Particle Arrays at Air-Water Interface Based on Silica Particles with Well-Defined and Highly Grafted Poly(Methyl Methacrylate). Polymer Engineering \& Science, 50, 1067-1074. https://doi.org/10.1002/pen.21639

[18] Mouri, E., Sakamori, H., Yoshinaga, K. and Nakato, T. (2014) Behavior of Polymer Chains Grafted from Latex Particles at Soft Interfaces. Colloid and Polymer Science, 292, 547-555. https://doi.org/10.1007/s00396-013-3097-4

[19] Karanam, S., Goossens, H., Klumperman, B. and Lemstra, P. (2003) "Controlled" Synthesis and Characterization of High Molecular Weight Methyl Methacrylate/ tert-Butyl Methacrylate Diblock Copolymers via ATRP. Macromolecules, 36, 8304-8311.

[20] Matsumoto, K., Wahnes, C., Mouri, E., Matsuoka, H. and Yamaoka, H. (2001) Synthesis of Anionic Amphiphilic Carbosilane Block Copolymer: Poly(1,1-diethylsilacyclobutane-block-methacrylic acid). Journal of Polymer Science Part A: Polymer Chemistry, 39, 86-92. https://doi.org/10.1002/1099-0518(20010101)39:1<86::AID-POLA100>3.0.CO;2-K

[21] Mori, H. and Muiller, A.H.E. (2003) New Polymeric Architectures with (Meth)acrylic Acid Segments. Progress in Polymer Science, 28, 1403-1439. https://doi.org/10.1016/S0079-6700(03)00076-5 